Sādhanā Vol. 38, Part 5, October 2013, pp. 1027-1050. (C) Indian Academy of Sciences

\title{
Regulatory practices for nuclear power plants in India
}

\author{
S S BAJAJ \\ Atomic Energy Regulatory Board, Mumbai 400 094, India \\ e-mail: ssbajaj@aerb.gov.in
}

\begin{abstract}
The Atomic Energy Regulatory Board (AERB) is the national authority for ensuring that the use of ionizing radiation and nuclear energy does not cause any undue risk to the health of workers, members of the public and to the environment. AERB is responsible for the stipulation and enforcement of rules and regulations pertaining to nuclear and radiological safety. This paper describes the regulatory process followed by AERB for ensuring the safety of nuclear power plants (NPPs) during their construction as well as operation. This regulatory process has been continuously evolving to cater to the new developments in reactor technology. Some of the recent initiatives taken by AERB in this direction are briefly described. Today, AERB faces new challenges like simultaneous review of a large number of new projects of diverse designs, a fast growing nuclear power program and functioning of operating plants in a competitive environment. This paper delineates how AERB is gearing up to meet these challenges in an effective manner.
\end{abstract}

Keywords. Regulation; nuclear safety; periodic safety review; consent; license for operation; radiation safety; environmental safety.

\section{Introduction}

Nuclear energy remains an important element in India's energy mix for sustaining rapid economic growth. The installed nuclear capacity in the country has reached $4780 \mathrm{MWe}$. Presently, there are 20 operating NPPs in India and India ranks sixth among the nations, in terms of the number of nuclear power reactors in operation. The construction work of two $1000 \mathrm{MWe}$ LWRs at Kudankulam, being set-up in technical cooperation with the Russian Federation is nearly complete. The Unit- 1 is in an advanced stage of commissioning and is likely to become operational soon. The unit-2 is expected to follow soon after. The 500 MWe Prototype Fast Breeder Reactor is also in an advanced stage of construction. Construction of four indigenously designed 700 MWe PHWRs, two each at existing sites of Kakrapar in Gujarat and Rawatbhata in Rajasthan is in progress. These seven plants under construction/commissioning gross to an additional capacity of 5300 MWe.

Today India is on the threshold of a quantum expansion of its nuclear power programme. There are plans to significantly increase the installed capacity in nuclear power by setting-up large light water cooled reactors of overseas design/vendors, apart from the indigenously designed PHWRs and Fast Breeder Reactors. The nuclear power programme in India is being pursued with full 
regard for nuclear and radiation safety, which encompasses safety of plant personnel, public and the environment around the plants.

The primary responsibility of ensuring safety of NPPs rests with the organisation responsible for the design, construction and operation of NPPs. In India, these activities are carried out by the Nuclear Power Corporation of India Ltd (NPCIL) and the Bharatiya Nabhikiya Vidyut Nigam (BHAVINI). The task of laying down necessary safety requirements and their enforcement are entrusted to the Atomic Energy Regulatory Board (AERB).

\section{Atomic Energy Regulatory Board and its regulatory structure}

The Atomic Energy Regulatory Board was constituted on November 15, 1983 to carry out certain regulatory and safety functions envisaged under Sections 16, 17 and 23 of the Atomic Energy Act, 1962. The regulatory authority of AERB is also derived from the rules and notifications issued under the Act. These include

- Radiation Protection Rules (2004)

- Working of Mines, Minerals and Handling of Prescribed Substances Rules (1984)

- Safe Disposal of Radioactive Wastes Rules (1987)

- Control of Irradiation of Food Rules (1996)

- Factories Rules (1996)

Prior to establishment of AERB, the regulatory functions were being carried out by the erstwhile Safety Review Committee of the Department of Atomic Energy (DAE-SRC), supported by Safety Committees for individual plants.

\subsection{The mission}

The mission of AERB is to ensure that the use of ionising radiation and nuclear energy in India does not cause unacceptable impact on the health of workers, members of the public and on the environment. AERB fulfills its mission by stipulating and enforcing requirements with respect to nuclear and radiological safety. In addition, AERB has also been given the mandate for overseeing industrial safety in all DAE units. This mandate is fulfilled by enforcing the Factories Rules.

\subsection{Powers and functions}

The Atomic Energy Regulatory Board has the powers to execute various functions to carry out its responsibilities. These include:

- Development of safety Codes, Guides and Standards to stipulate requirements applicable for siting, design, construction, commissioning, operation and decommissioning of nuclear and radiation facilities and for conduct of regulatory and safety functions;

- Carrying out safety reviews of nuclear and radiation facilities under design, construction and operation;

- Ensuring compliance by nuclear and radiation facilities with the stipulated safety requirements;

- Issuing regulatory consents for siting, construction, commissioning, operation and decommissioning of nuclear and radiation installations; 
- Organising and conducting regulatory inspections and enforcing corrective actions as necessary, at the facilities being regulated;

- Assessment of radiological safety status with regard to personnel exposures and environmental radioactivity releases in nuclear and radiation facilities;

- Administering the provisions of the Factories Act, 1948 in the Units of the Department of Atomic Energy;

- Reviewing the emergency preparedness plans prepared by nuclear installations and participating in emergency preparedness drills as observers;

- Funding safety research and training activities related to regulatory functions;

- Keeping the general public informed on major issues concerning nuclear, radiological and industrial safety.

\subsection{Organisation}

The Board of AERB consists of a Chairman, five members and a secretary appointed by the Government of India. While the Chairman, Secretary and one of the members (Chairman of SARCOP is ex-officio member) are full time employees of AERB, the other four are persons of repute from major national and academic institutions and serve on the Board as part time members. The Board reports to the Atomic Energy Commission.

AERB carries out its functions with the help of a secretariat consisting of seven Scientific/Technical Divisions and a Safety Research Institute. The Secretariat is supported by an Administrative and an Accounts Division. The organisation chart is shown in figure 1.

AERB is supported in its work by an elaborate committee structure. The apex committees are the Safety Review Committee for Operating Plants (SARCOP), Safety Review Committee for Applications of Radiation (SARCAR) and Advisory Committees for Project Safety Review (ACPSRs). SARCOP is involved in safety surveillance and enforcement of safety stipulations in the operating units of DAE. SARCAR is involved in review of radiation safety in applications of radiation and use of radioactive sources in medical, industrial and research applications. ACPSRs carry out safety review of the NPPs and fuel cycle projects under construction/commissioning and make recommendations to AERB regarding issuance of regulatory consents for different stages of the projects under construction.

AERB is also supported by another Advisory Committee, the Advisory Committee on Nuclear Safety (ACNS) which advises AERB on generic issues affecting safety of the nuclear facilities and regulation. ACNS also makes recommendations on the safety codes, standards, guides and manuals prepared for siting, design, operation, quality assurance, regulation and decommissioning/life extension of nuclear facilities. These documents are prepared by the respective committees for each of these areas.

For the purpose of safety review and surveillance of the nuclear facilities including Nuclear Power Plants and fuel cycle facilities, AERB has established multi-tiered system of safety committees to support the safety assessment and consenting process being carried out by AERB and its technical divisions. These committees comprise of experts in relevant areas from organisations within DAE and in many cases from reputed academic institutions and other governmental agencies. In the case of operating plants, these committees function under the framework of SARCOP and in the case of projects under construction, under the respective ACPSRs. While the multi-tiered system of committees provides support with respect to safety review and regulatory decision making, the responsibility for ensuring that the regulatory decisions and enforcement are in line with the mission, policies and regulatory documents of AERB, lies with AERB and the respective technical divisions. 


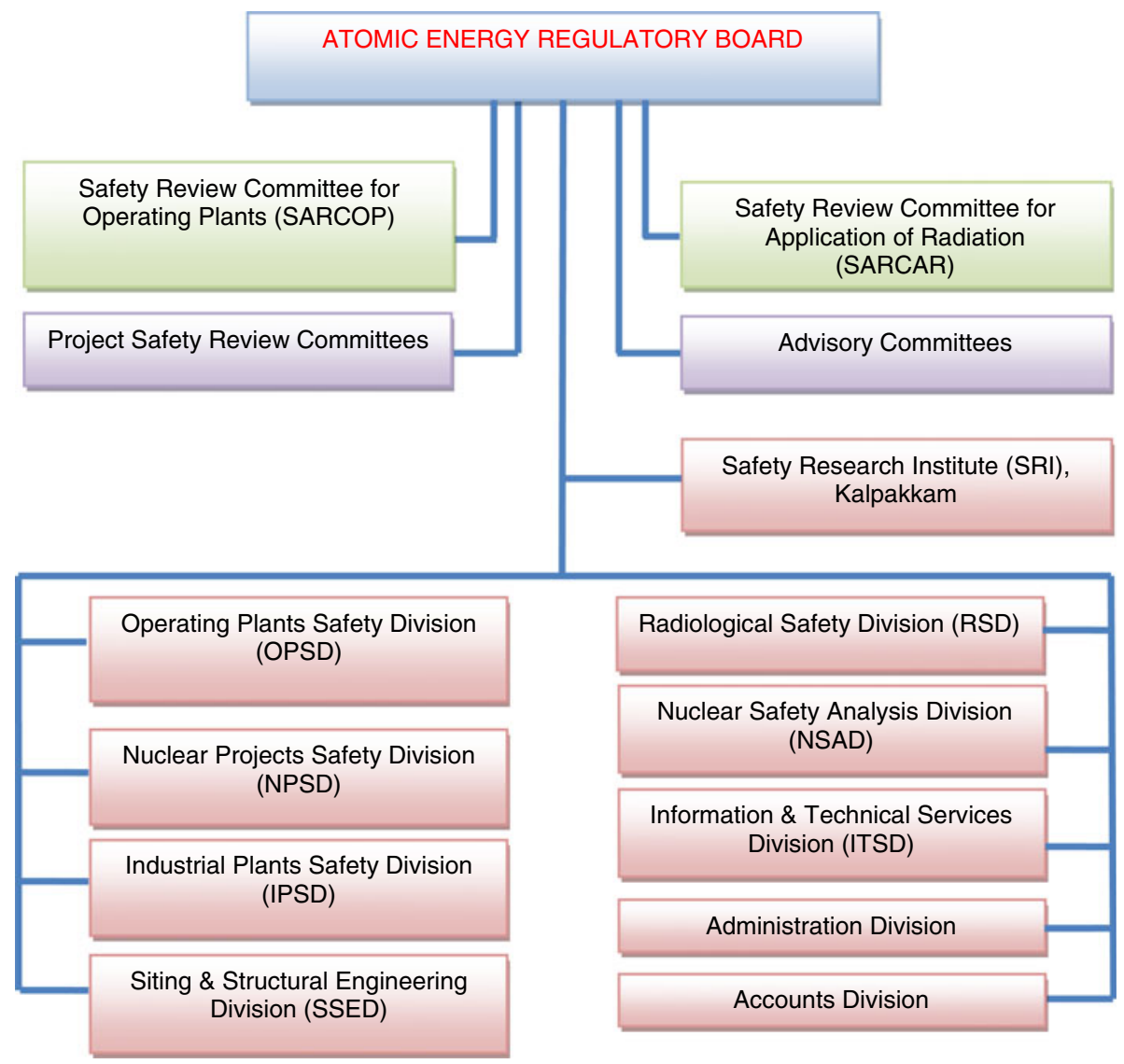

Figure 1. Organisation chart of AERB.

Among the various technical divisions of AERB, the nodal division responsible for regulatory activities with respect to the operating NPPs is the Operating Plants Safety Division (OPSD), which also serves as the secretariat of SARCOP. For the projects under construction/commissioning, the nodal division is the Nuclear Projects Safety Division (NPSD) which also serves as the secretariat for the ACPSRs. The nodal division for regulatory activities related to the fuel cycle facilities and industrial safety aspects of all facilities is the Industrial Plants Safety Division (IPSD).

\section{Development of safety documents}

One of the mandates of AERB is to develop safety documents in the form of codes, guides and manuals that lay down requirements for meeting the safety criteria for siting, design, construction, commissioning, and operation of different types of plants and facilities. Soon after its formation in 1983, AERB initiated work in this direction with the help of experts with extensive experience in the relevant fields. Safety documents published by the International Atomic Energy Agency and regulatory bodies of other countries are appropriately used as reference material 
for the purpose. Experience gained in designing and operating Nuclear Power Plants and other nuclear facilities in India is also reflected in the material contained in AERB documents.

The safety codes establish objectives and set minimum requirements that have to be fulfilled to provide adequate assurance for nuclear and radiation safety. The safety guides provide guidelines and indicate acceptable methods for implementing specific requirements prescribed in the codes. In addition, AERB also develops safety manuals that elaborate on specific aspects and contain detailed technical information and procedures in certain areas.

Presently, AERB has an established process for development of these regulatory documents and has set-up an elaborate mechanism for the same. The framework established by AERB involves a multi-tier system of committees of experts, which regularly reviews and takes decisions with respect to (a) identifying the need for development of specific documents, (b) assigning priority and (c) the contents of the documents that are being developed, on case by case basis, keeping in view the facilities and activities being regulated and the regulatory activities/safety aspects being handled.

Using this framework, AERB has so far published 141 regulatory documents concerning different aspects of regulation and safety aspects of the facilities and activities that it regulates. Of these, over 100 documents are related to regulatory and safety aspects of NPPs. AERB has published codes and guides covering aspects of siting, design, operation, radioactive waste management, quality assurance, radiation protection, emergency preparedness and regulation of NPPs. These codes and guides establish the requirements pertaining to all phases of the lifecycle of NPPs. A list of documents related to NPPs is given in Annexure A. All these safety documents are being extensively utilized in developing designs and operating procedures as also in regulation activities including safety reviews by AERB.

\section{Safety review of nuclear power projects}

\subsection{The review process during project stage}

AERB has established an elaborate system for in-depth safety review of Nuclear Power Projects. For this purpose, different stages of 'regulatory consent' have been identified. These stages are: Siting, Construction and Commissioning.

The regulatory process of AERB provides for issue of 'consents' for these stages of the NPP, based on detailed safety review and assessments for ensuring compliance to the specified regulatory/safety requirements.

The safety review process for these stages of a project is briefly described below

4.1a Siting: Safety review of the proposed site is carried out as per the requirements laid down in AERB's Code on Siting of Nuclear Power Plants. The review for 'siting' covers the site evaluation report and the design basis information of the NPP. The aspects considered in this phase include the geological, seismological and meteorological characteristics of the site, population distribution around the site, land use and water use, distance of the site from nearest public roads, airports, chemical and explosive storage points, availability of a large water body nearby, etc., against the norms specified in the code. In addition to these, the review by AERB also addresses aspects related to emergency preparedness, in particular the suitability of the proposed site and the surrounding areas, with regard to implementability of emergency response measures. A key requirement of AERB with respect to siting of the NPP is to maintain an 'exclusion zone' around the NPP, inside which no residence or any other public activity is permitted. Besides, a 'sterilised zone' around the exclusion zone is also identified, where only natural growth of 
population is permitted in order to ensure that the number of people to be managed in the event of an emergency is limited.

For siting of an NPP, in addition to the 'siting clearance' from AERB, the utility (operator of the proposed NPP) is required to obtain clearances from the Ministry of Environment and Forests of Government of India and other statutory bodies like the Central and the respective State Pollution Control Boards.

4.1b Construction: Clearance for start of construction of the NPP requires a detailed 'design review' of the plant design, by way of review of the Preliminary Safety Analysis Report (PSAR). The PSAR provides general information on plant design and details of the Design Basis of the reactor and all its auxiliary systems as also safety analysis for various operating states, including normal operation, transients, upset plant conditions, design basis accidents and also beyond design basis accidents. These analyses are based on a set of Postulated Initiating Events (PIE), both internal and external to the plant, as prescribed by the AERB's Code on Design of NPPs and associated Safety Guides on the subject. Apart from the plant design, design basis and safety analysis, the Quality Assurance (QA) aspects during design and construction, construction schedule and the construction safety management aspects are reviewed in detail for compliance to the requirements specified in the relevant Code/guides/standards, before AERB considers issuing the construction clearance for an NPP.

These reviews are conducted by the Project Design Safety Committee (PDSC) and its expert working groups at the first level, followed by review of the findings and recommendations of the PDSC by the Advisory Committee for Project Safety Review (ACPSR) at the second level. On matters pertaining to regulatory consent of the nuclear power plant at various stages, the Board of AERB performs the third level of review based on recommendations of the PDSC and ACPSR. The multi-tier review process for Nuclear Power Projects is schematically shown in figure 2.

AERB's regulatory process provides for issue of 'consent for construction' of the NPP in three sub-stages, called clearance stages, namely, start of excavation, first pour of concrete/construction of main plant buildings, erection of major equipment.

Each of these sub-stages has specific prerequisites in terms of submission of applications and information and their regulatory review. The regulatory review process of the project is staggered and clearance for a particular sub-stage is given based on the completion of design safety review relevant to that sub-stage. This scheme has been devised to permit parallel action for detailed review while site work for construction can also proceed simultaneously.

4.1c Commissioning: Completion of construction of the plant and its systems is followed by commissioning. Commissioning is the process by which constructed plant components and

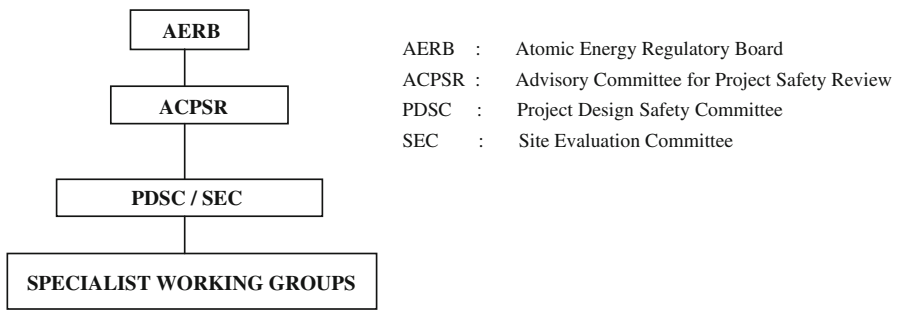

Figure 2. Multi-tier review process for nuclear power projects. 
systems are brought into service and are tested to ensure that their performance is in conformance with the design intent. This is generally done in a progressive manner as the construction activities related to various plant systems are completed. Normally, the commissioning of items like service systems are taken up soon after their construction is completed while construction of other reactor systems proceeds in parallel. Commissioning is also a stage at which the ownership of the systems/plant is handed over from the construction organisation to the commissioning/ operating organisation, requiring assurance of compliance of a number of aspects.

The regulatory reviews for commissioning clearance are aimed to ensure compliance to these. The main aspects that are considered in review for commissioning clearances include (a) completion of construction in accordance with the approved design and quality standards, (b) review of acceptability and resolution of any deviations from the approved design and their documentation, (c) availability of commissioning plans, schedules and procedures, (d) availability of adequate number of trained and qualified personnel, (e) quality assurance plan for commissioning, (f) framework for reporting, review and documentation of results of commissioning, etc.

The regulatory mechanism provides for issue of commissioning clearances in stages, similar to the construction clearances as mentioned earlier. Clearances for these stages are considered based on to the construction clearances earlier satisfactory review of the results of commissioning of the proceeding stages and resolution of any issues that are identified. These reviews are done by the multi-tiered system involving PDSC, its working groups and the ACPSR. The clearances are considered by the Board of AERB after scrutinising the results of the reviews by PDSC $\&$ ACPSR and their recommendations.

The stages at which the commissioning clearances are considered for a Pressurised Heavy Water Reactor based NPP are typically:

- initial fuel loading

- commissioning of coolant and moderator systems with light water

- hot conditioning/passivation of Heat Transport system,

- charging heavy water into the system

- first approach to criticality of the reactor

- reactor physics measurements/tests/calibration

- Commissioning tests and monitoring of performance of plant systems at various steps of increasing reactor power levels up to rated capacity, to check the dynamics of plant systems and transient response.

Commissioning clearances for the NPPs of other designs also follow a similar system of stagewise reviews and clearances. Results of the above commissioning tests and reviews are required to be incorporated in the PSAR of the plant, to produce the Final Safety Analysis Report (FSAR), which forms the basis for the operating license of the NPP.

In addition, the 'Technical Specifications for Operation of the NPP' are also developed on the basis of the FSAR and the safety reviews, which lays down 'safe operating envelope' for the NPP, in terms of limits and safety margins on various plant operational and safety parameters, settings of various protection systems for automatic actions, limits for various operator actions, requirements of inspections, testing and surveillance of key plant systems and equipment for ensuring their health and availability, requirements with respect to number of trained and qualified staff for safe operation of the NPP, requirements with respect to documentation and reporting and organisational and administrative requirements for safety management of the NPP. In short, the approved technical specifications define the domain of plant operation for ensuring compliance to the regulatory requirements and design assumptions and assure a plant configuration in accordance with the approved design which ensures a very high level of safety. 
In these reviews and clearances, consideration is also given to ensure certain other milestones and pre-requisites such as establishment of appropriate emergency preparedness measures and demonstration of the emergency response capability, prior to first criticality.

4.1d Regulatory inspections during construction and commissioning: In addition to detailed reviews during construction and commissioning through the multi-tiered committees, AERB carries out regulatory inspections of the projects, to ensure that safety requirements in construction are appropriately followed and all pre-requisites are fulfilled before going to next stage in construction or commissioning. Typically, 3 or 4 such inspections are conducted in a year depending on the stage of the project. Observations from these inspections are appropriately considered for any enforcement measures and granting of the regulatory consents.

\subsection{Project safety reviews currently in progress}

Presently seven NPPs are under various stages construction/commissioning in India. The two 1000 MWe pressurised water reactors of VVER-1000 : model V-412 being built at Kudankulam (KK - 1\&2), with cooperation from the Russian Federation, are in a very advanced stage of construction and commissioning. Construction activities have been completed for unit -1 of this NPP and the commissioning activities are in an advanced state. AERB has granted permission for initial fuel loading and first approach to criticality of this unit, based on extensive safety reviews. As per the present schedules, this unit is expected to become operational soon. Unit - 2 of this NPP is expected to enter the commissioning phase in the near future after completion of the construction activities.

Construction of the 500 MWe Prototype Fast Breeder Reactor (PFBR), a Uranium OxidePlutonium Oxide fuelled fast neutron reactor, which employs liquid sodium as the reactor coolant, being built at the Kalpakkam site is nearing completion. Design of PFBR has been developed by the Indira Gandhi Centre for Atomic Research (IGCAR) at Kalpakkam in Tamil Nadu state. This reactor being of an entirely different design concept, "Safety criteria for design of PFBR" was developed by AERB first and the guidelines given in this document were subsequently used for review of PFBR design. Considering the fact that PFBR is first power reactor of its kind, AERB has broadened the scope of its review work and insisted on extensive analysis and testing of many of the equipment and systems that are being used in this NPP, to demonstrate their effectiveness.

In addition to these, four units of indigenously designed PHWRs of 700 MWe capacity are under construction since 2010, two each at the existing sites at Kakrapar and Rawatbhata. The design of these reactors is an extension of the proven design employed at the $540 \mathrm{MWe}$ units operational at the Tarapur site, and employs additional design and safety features. Design review related to construction clearance for these reactors is presently in progress.

\section{Regulatory review of operating NPPs}

\subsection{The review process during operation}

Presently there are twenty NPPs in operation in India. These include the two boiling water reactors (BWR) at Tarapur and 18 PHWR units, owned and operated by the Nuclear Power Corporation of India. For the purpose of regulation of safety of NPPs in operation, AERB has laid down requirements relating to the role of AERB, NPCIL headquarters and individual plant 
managements. In addition, specific requirements pertaining to educational qualifications, training requirements and licensing of operating personnel are also prescribed. Other requirements specified by AERB deal with operational limits and conditions; operating instructions and procedures; maintenance, inspection and periodic testing; radiation protection, radioactive effluents and waste management; security aspects; review and audit functions and emergency preparedness. All these requirements are specified in AERB's 'Code of Practice on Safety in Nuclear Power Plant Operation.' Elaboration and guidelines on methods for fulfilling the requirements of the code are given in a number of 'Safety Guides' on individual topics, issued by AERB. Enforcement of the operating rules and regulations is accomplished through an elaborate safety review mechanism established by AERB.

AERB issues 'license for regular operation' of the NPP, based on review of the NPP's performance at rated power within the commissioning consent. The period for power operation within the commissioning consent is normally about 100 full power days. While applying for license for regular operation, the applicant has to submit the FSAR, reflecting the as built design approved by AERB, detailed performance reports, status of and measures to resolve any pending issues. Subsequent to grant of this authorisation, the responsibility of safety review is transferred from the ACPSR to the Safety Review Committee for Operating Plants (SARCOP)/Operating Plant Safety Division (OPSD). This signifies end of project stage and the NPP formally comes under the purview of safety review mechanism for operating facilities.

As per the present regulations, AERB issues the license for operation of the NPP for a maximum period of five years, beyond which the NPP has to seek a renewal of the license for operation as per the prescribed requirements.

5.1a Safety review of the NPP during the period of license for operation: As indicated earlier, license for operation of the NPP is issued by AERB for a maximum duration of five years. During this period, the NPP is continuously under regulatory review by AERB, which includes the following:

(i) Review of periodic reports submitted by the plant as per reporting criteria specified in the license for operation. (ii) Review of significant events. (iii) Radiological safety status including radiological conditions in the plant, radiation exposures to the plant personnel, radioactive waste management and radioactivity discharges to the environment. (iv) Adherence to quality assurance and safety management aspects. (v) Periodic regulatory inspections. (vi) Review of proposals for modification in hardware, control logics, plant configuration and procedures related to safety and safety related system. (vii) Reports of special investigation committees and/or special regulatory inspections following an event of major safety significance.

The overriding consideration of the safety review/surveillance by AERB within the period of license for operation of the NPP is 'adherence to the approved Technical Specifications'. In case of any deviations or non-compliances, AERB initiates appropriate enforcement actions, depending on the safety significance of the deviation. The enforcement measures resorted to by AERB for such cases can range from issuance of written directives for restoration of compliance to the requirement, restrictive measures including curtailment/suspension of operation to suspension/revocation of the operating license. These safety reviews are carried out through a multi-tiered review process. The multi-tiered review process for the operating NPPs is given in figure 3 .

Another important consideration in the safety review/surveillance by AERB is the high level of importance given to operating experience feedback (OEF), wherein lessons learned from the experience elsewhere are utilized to effect improvements in the plant hardware and practices, as 


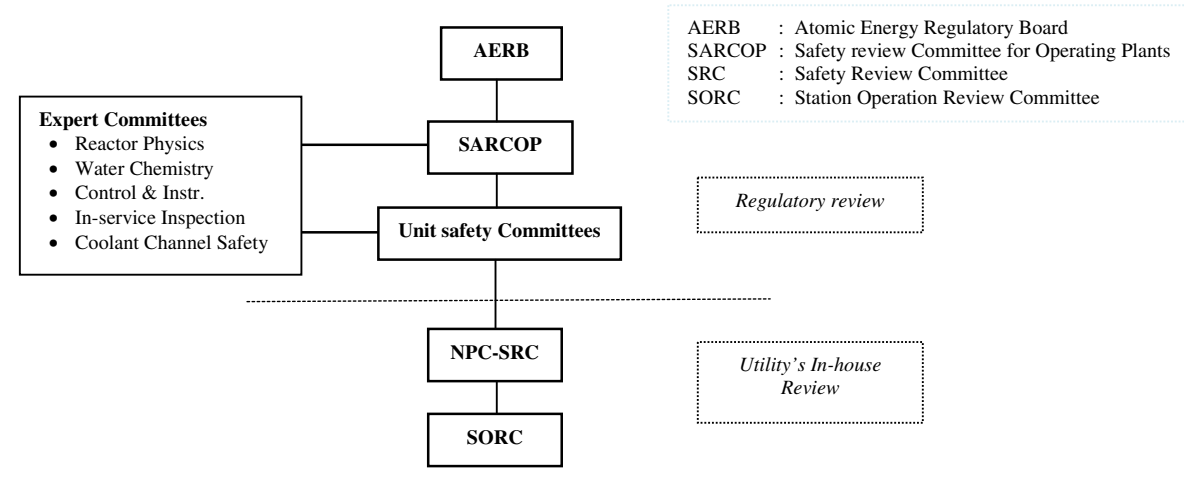

Figure 3. Multi-tire review process for operating NPPs.

relevant and appropriate for our NPPs. The experience feedback available from the Indian NPPs as well as overseas plants is utilized in this respect. AERB extensively uses the inputs from the Incident reporting System (IRS) of the International Atomic Energy Agency for this puprose. A large number of improvements have been incorporated in our NPPs in the past, through the OEF route. The improvements in fire safety measures following the turbine building fire incident at NAPS in 1993, improved flood safety measures following the flood incident in KAPP in 1994, inspection and health assessment efforts related to reactor core shrouds in the BWRs at TAPS, inspection and health assessment of feeder pipes in the primary heat transport systems of all PHWRs and institution of a monitoring programme for 'flow assisted corrosion' are only a few examples of such improvement.

In addition to the above, special reviews are also undertaken following an event or occurrence of major safety significance in India or abroad, to assess their impact on safety and need for any corrective measures.

5.1b Safety review for renewal of authorization: As per present regulations, the license for operation of the NPP is issued for a maximum period of five years, beyond which it needs to be renewed as per prescribed guidelines. These safety reviews are of two types, a limited scope safety review called Application for Renewal of Authorisation (ARA) every five years and a very comprehensive full scope review called Periodic Safety Review (PSR) every ten years.

The scope and depth of review required for PSR are detailed in AERB safety guide for renewal of authorisation of NPP. In either cases the NPP is required to carry out a self-assessment of plant safety as per the specified scope and guidelines and prepare a report, which needs to be submitted along with the application for renewal of license for operation of the NPP, for regulatory review and assessment by AERB.

Application for Renewal of Authorisation: Towards the end of authorisation period, the NPP has to submit an Application as per the requirement of ARA to provide assurance to AERB that the NPP as a whole continues to be capable of safe operation.

This application requires that a limited review (not as exhaustive as PSR described further) of certain important aspects of plant operation such as safety performance, operating experience feedback, in-service inspection and major modifications carried out during the period. The report of such review provides an opportunity for systematic and integrated assessments of the status of the plant. Such a review monitors trends and detects early signs of degradations, if any. 
Based on findings of this self-assessment and regulatory review of this ARA, AERB decides on renewal of license for continued operation of the NPP, for a maximum period of five years.

Periodic Safety Review (PSR): For PSR, AERB has issued a safety guide AERB/SG/O-12 on 'Renewal of Authorisation for operation of NPPs'. This document lays down the requirement for carrying out a comprehensive PSR, which should be carried out once in ten years. The requirements of PSR are in line with the IAEA Safety Guide on Periodic Safety Review. PSR establishes requirements for safety assessment, which takes into account improvements in safety standards and practices, cumulative effects of plant ageing, modifications, feed back of operating experience and development in science and technology.

As per the requirement of PSR, the NPP is required to carry out a comprehensive selfassessment covering the safety factors identified in the guide. The purpose of the self-assessment by the NPP is to identify the strengths and shortcomings of the NPPs against the requirements of current standards/practices. Based on this assessment, modifications or upgrades required to compensate for any safety significant shortcomings are required to be identified. The report on the PSR is subjected to regulatory review in the multi-tier review process for satisfactory resolution of the shortcomings.

The PSR covers a number of 'safety factors', as identified in the AERB safety guide for renewal of authorisation, which address nearly all aspects and management systems that governs the safety of the NPP. The current list of safety factors considered for the PSR are (i) actual physical condition of the plant, (ii) safety analysis, (iii) equipment qualification, (iv) management of ageing, (v) safety performance, (vi) use of experience from other NPPs and research findings, (vii) procedures, (viii) organisation and administration, (ix) human factors, (x) emergency planning and (xi) environmental impact.

Invariably the PSR results in identification and implementation of a host of measures for upgrading safety of the NPP and to address issues of ageing of components, to keep it abreast of the changing safety practices and expectations. Thus PSR is an important regulatory instrument for maintaining and improving high levels of safety throughout the operating life cycle of the NPP.

PSRs done in Indian NPPs: AERB has formally introduced the requirement of PSR as a prerequisite for license renewal in 2001. In fact India is one the first countries to introduce the system of PSR as a pre-requisite for license renewals and continued operation of NPPs. Since then a number of NPPs have completed the PSRs in a phased manner, particularly the ones that have been in operation for longer periods (TAPS 1\&2, RAPS 1\&2, MAPS 1\&2, NAPS $1 \& 2$, KAPS $1 \& 2$, KGS $1 \& 2$, RAPS $3 \& 4$ and TAPS $3 \& 4$ ). These PSRs have been helpful in implementing many safety upgrades, particularly in the older plants and instituting systematic programme for ageing management.

Significant safety enhancements implemented in the three older NPPs namely RAPS-1\&2, MAPS-1\&2 and TAPS-1\&2, based on PSR are given below,

RAPS-1\&2:

- Installation of two additional SBO (station blackout) diesel generators (air-cooled) at higher elevation, to ensure availability of emergency power in case of flooding due to postulated failure of upstream dam.

- Provision for connection of fire tenders for additional back up for core cooling.

- Provision for water make-up to dousing tank using fire tenders to enable continued water injection to steam generators.

- Additional air accumulators for supplying instrument air to essential loads in reactor building. 
- Identification of water sources in case of failure of down-stream side dam.

- Addition of high pressure injection in the ECCS (emergency core cooling system).

- Segregation of power and control cables for safety related loads.

- Up-gradation of fire protection systems.

- Addition of supplementary control room.

- Seismic re-evaluation and seismic upgrades.

MAPS-1\&2:

- Re-location of UPS (uninterrupted power supply systems) to higher elevation.

- Construction of Tsunami protection wall.

- Installation of Tsunami warning system.

- Addition of high pressure injection in the ECCS (emergency core cooling system).

- Additional air accumulators for supplying instrument air to essential loads in RB.

- Segregation of power and control cables for safety related loads.

- Up-gradation of fire protection systems.

- Addition of Supplementary Control Room.

- Seismic re-evaluation and seismic upgrades.

TAPS 1\&2:

- Augmentation of emergency power supply system by addition of $3 \times 100 \%$ seismically qualified, physically separated diesel generators (DG) located at higher elevation, in place of the original $3 \times 50 \%$ capacity DGs.

- Unit wise segregation of Emergency Power supply for safety systems.

- Additional SBO (station blackout) diesel generator.

- Additional battery banks at higher elevation.

- Unit-wise segregation of residual heat removal systems.

- Incorporation of a dedicated fuel pool cooling system.

- Augmentation of Emergency feed to reactor coolant system.

- Physical separation of cables for redundant trains of safety systems.

- Addition of Supplementary Control Rooms.

- Seismic re-evaluation and seismic upgrades.

In addition to these major safety upgrades in the older NPPs, the PSRs have helped in a host of other improvements in all the NPPs. Most important among these include review and updating of the safety analysis reports of the NPPs to reflect the current plant configuration and to include safety analyses to address the current list of initiating events, using state of art analytical tools and analysis methodology. In addition, all these NPPs now have systematic programmes for 'ageing management of important systems, structures and components of the plants' and ensure 'maintenance of adequate equipment qualification over the plant life'. Additionally extensive reviews were done for optimising the programme for in-service inspection of systems and components at the NPPs.

5.1c Regulatory inspections during operation: During operation stage, regulatory inspections are carried out twice in a year to assess and verify compliance to the regulatory requirements. Besides the routine regulatory inspections, AERB also conducts special regulatory inspections with specific objectives as deemed necessary. Such inspections may be taken up in case of significant events or after major modifications to the plant. During inspection, the compliance of the regulatory requirements and the technical specifications is checked by review of records and 
other documents maintained by NPPs, field visits and interaction with the plant personnel. The observations made during these inspections forms an important input to the safety review and enforcement machinery of AERB.

5.1d Licensing of operating personnel: Licensing of plant personnel is another important aspect of AERB's responsibilities. It is a mandatory requirement that the personnel in operational positions at NPPs should be formally licensed and qualified for various levels by AERB. The entire process is exhaustively documented in two manuals, 'Licensing procedure for operating personnel' and 'QA manual for station licensing examination'. The competence requirement and the depth of knowledge and skills for each operational position are verified through a series of performance and knowledge checks prescribed in these manuals. Final verification is done through a written examination followed by certification by the AERB Committee. The licenses are valid for a period of three years and have to be renewed thereafter according to the prescribed procedure.

5.1e Control of radiation exposures: Protecting radiation workers in NPPs from undue radiation exposures is one of the prime objectives of the regulatory body. AERB is empowered by the competent authority to enforce provisions of Atomic Energy (Radiation Protection) Rules, 2004. Under this rule, AERB specifies safety directives, the dose limits for the radiation workers as well as for the member of public. AERB has prescribed a dose limit of $100 \mathrm{mSv}$ over a period of five consecutive years and an annual limit of $30 \mathrm{mSv}$ for radiation workers. The annual limit of $30 \mathrm{mSv}$ specified by AERB is more stringent than the ICRP recommended limit of $50 \mathrm{mSv} / \mathrm{Yr}$. AERB has also specified an investigation level at $20 \mathrm{mSv} / \mathrm{Yr}$. A standing committee reviews the circumstances under which any radiation worker in the country has been exposed to more than $20 \mathrm{mSv}$ in any particular year. This review is in addition to the review by the in-house committees at the NPPs, as per AERB requirements. Finding the root cause for exposures exceeding these limits and suggesting remedial measures to reduce such exposures in future are the prime objectives of such review. AERB ensures that all the radiation protection measures are in place through its continuous safety monitoring process as well as periodic regulatory inspections.

Another key area of AERB's review in relation to dose to the occupational workers at the NPPs is the annual budget on collective radiation exposures. AERB has specified a requirement for all plants to prepare an annual budget, taking into account of the planned activities for the year, with the objectives of optimizing the planned exposures as well as meeting 'ALARA' (as low as reasonably achievable) targets. A key aspect of these dose budgets has been the thrust given with respect to exploring and implementing in a planned manner, measures for maintaining and lowering of radiation background levels at key areas in the NPPs by way of better operational practices, design changes, housekeeping and decontamination efforts. The efforts put in by AERB and the NPPs in this regard during the last two decades have helped in reducing the collective dose consumption in the Indian NPPs to the levels close to the international averages, even with the significantly higher use of manual labour employed in the Indian NPPs.

5.1f Controlling environmental releases: Environmental surveillance of all NPPs is done by the Environmental Survey Laboratories (ESL) established at the NPP sites. These laboratories are established well before the plant goes into operation to enable collection of data on account of background radiation. The radiological impact due to operation of these plants is assessed on a continuous basis by collection and analysis of samples of items of diet i.e., vegetables, cereals, milk, meat, fish, etc. 
The aspects related to generation, management and environmental discharge of radioactive effluents from the NPP during the operational phase are regulated by AERB, in accordance with the Atomic Energy (Safe Disposal of Radioactive Wastes) Rules, 1971. In accordance with this, AERB has established limits on discharge of effluents through the gaseous and liquid routes. In addition, limits are also set for the solid wastes that can be stored at the on-site solid waste facilities. AERB has a robust system for closely monitoring and regulating compliance to these limits.

The impact of radioactivity discharges from the NPPs are monitored regularly by the ESLs and reported to AERB. The effectiveness of the system for regulation of radioactive effluents from the NPPs is evident from the practically insignificant radiological impact of the NPPs. The radiation dose in the vicinity of the NPPs has remained at an insignificant fraction of the internationally accepted norm of $1 \mathrm{mSv} / \mathrm{yr}$.

\section{Regulatory effectiveness and safety status of the NPPs}

The real evidence of effectiveness of a nuclear regulator lies in the safety record of the NPPs under its regulatory control. The safety performance of Indian NPPs has over the years remained satisfactory and in tune with the international benchmarks. There has not been any nuclear accident in any of the NPPs in India. The radioactivity discharges from the Indian NPPs have also been kept very low and is on par with the international averages. The radiation exposures to the public due to discharges from the operating NPPs have remained a very low fraction of the limits specified. The average radiation exposures to the occupational workers also have remained on par with the international benchmarks. Figures 4 and 5 illustrate the status of radiation exposures to the occupational workers and the public during the last five years.

The table 1 given here shows the number of significant events in the Indian NPPs during the last five years, in terms of the corresponding INES (International Nuclear Event Scale) ratings. It should be noted that there has not been any event rated at level 4 or above in the INES, in

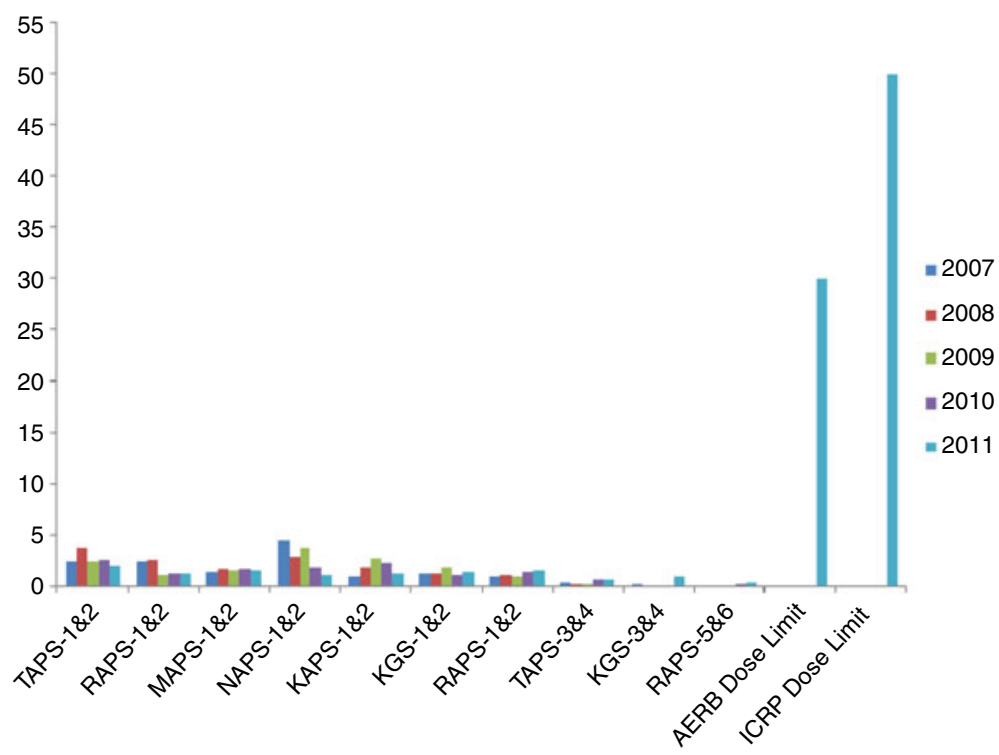

Figure 4. Average dose among monitored persons during the period 2007-2011 (mSv/Year). 


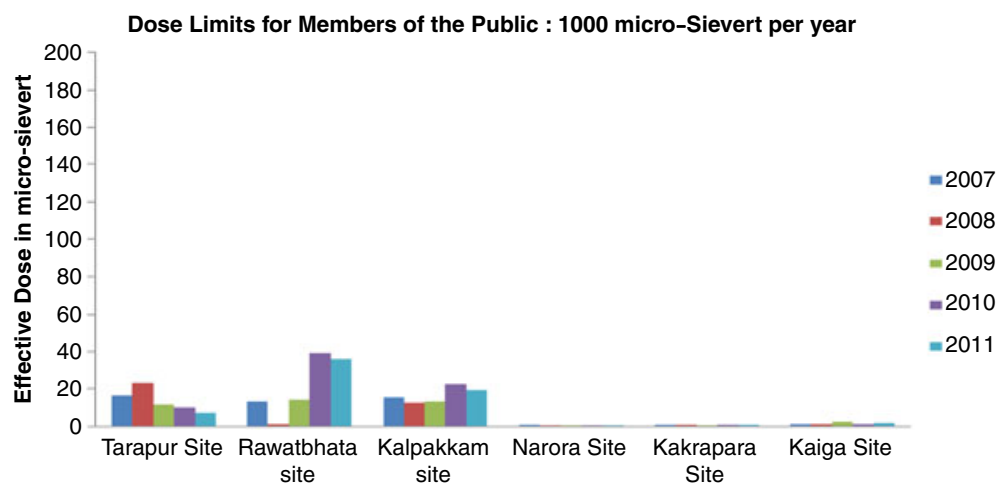

Figure 5. Effective dose to public at $1.6 \mathrm{~km}$ distance from NPPs.

the history of the Indian NPPs. There was only one event of INES level 3, which was the fire incident in the turbine building at NAPS unit-1 in March 1993.

\section{Looking ahead}

India is presently looking for a large expansion of its nuclear power programme. With the easing of international civil nuclear trade, it is expected that we will have many new plants of foreign design vendors. Additionally, the recent nuclear accident at the Fukushima nuclear power plant has resulted in nuclear safety issues being looked at afresh with increased safety expectations, all over the world. Today, there is a growing demand for increased transparency in matters relating to nuclear safety and regulatory matters. Also, there are increasing demands for having international harmonisation of the safety standards/practices. All of these pose additional demands on AERB, in terms of increased regulatory resources and enhanced competence. The efforts by AERB for meeting these demands are discussed below.

\subsection{Assessment of safety of NPPs in view of accident at Fukushima NPPs}

On March 11, 2011, a massive earthquake and tsunami caused extensive damage to the nuclear reactors and spent fuel pools at the Fukushima Nuclear Power Plant in Japan, releasing radioactivity into the environment. The accident at Fukushima opened a new perspective on nuclear safety, wherein the safety of the NPPs in case of severe external conditions and multiple failures needs reassessment.

Table 1. INES Rating of Significant events of Indian NPPs.

\begin{tabular}{lrrrrr}
\hline INES Rating & 2007 & 2008 & 2009 & 2010 & 2011 \\
\hline 0 & 28 & 22 & 23 & 33 & 36 \\
1 & 8 & 2 & 0 & 1 & 1 \\
2 & 0 & 0 & 0 & 0 & 1 \\
3 & 0 & 0 & 0 & 0 & 0 \\
$>3$ & 0 & 0 & 0 & 0 & 0 \\
Total & 36 & 24 & 23 & 34 & 38 \\
\hline
\end{tabular}


AERB initiated action for assessment of safety of Indian nuclear plants against severe external events. AERB asked NPCIL to carry out a comprehensive reassessment of safety against external events and emergency mitigation measures at all Indian NPPs. NPCIL constituted separate task forces to review safety of NPPs when subjected to non-availability of offsite and onsite electric power and water supply sources. These task forces were constituted based on the reactor types of different designs/vintage in India. Independently, AERB constituted a High Level Committee (AERBSC-EE) with national level experts to assess the safety of Indian NPPs against severe external events exceeding the design basis of the plant. The committee reviewed the capacity of Indian NPPs to withstand earthquakes and other external events such as tsunamis, cyclones and floods and the adequacy of provisions available to ensure safety in case of such events, both within and beyond design basis. The Committee noted that Indian Pressurised Heavy Water Reactors (PHWRs) have certain specific design safety features such as two independent shut down systems, low pressure and low temperature moderator system, water filled vault surrounding the calandria, capability to enable natural circulation for decay heat removal, etc. which provide advantages especially while dealing with the consequences of severe external events. For PHWRs cooling of the reactor core during shut down state can also be achieved by natural convection flow of reactor coolant through steam generators. This is achieved by charging water to the secondary side of the steam generators using backup design provisions like diesel engine driven pumps. This mode of core cooling can be maintained even under total loss of electrical power supplies. The efficacy of this design feature was amply demonstrated during the $17 \mathrm{~h}$ long SBO caused by the turbine hall fire incident at Narora unit-1 in 1993 when reactor core cooling could be successfully maintained.

The two BWRs at TAPS-1\&2 have passive Emergency Condensers for decay heat removal. The plant configuration allows the emergency condenser to be taken in case of a station black out (SBO), where no power supply is available. The water inventory available in the secondary side of the emergency condenser is adequate to provide decay heat removal from the reactor core for $8 \mathrm{~h}$. Notwithstanding the strength of Indian NPPs, AERBSC-EE made certain recommendations to strengthen the safety of NPPs for external events of magnitude beyond the design basis. All recommendations of the high level committee were accepted by AERB. Necessary steps have already been taken by AERB to ensure implementation of the recommendations appropriately in a time bound manner, at all the nuclear plants.

Post Fukushima, AERB has carried out special regulatory inspections of all NPPs to assess capabilities of NPPs and their preparedness to deal with the situations arising out of extreme natural events resulting from flood, tsunami, earthquake, etc. as well as the events of SBO. The inspections have shown that NPPs in India are adequately equipped to handle situations arising from external events of severe magnitude and additional arrangements being provided at these NPPs would be effective in ensuring the availability of safety functions in such situations including total loss of electrical power and unavailability of water through the designed sources.

Taking cognisance of the reports submitted by AERBSC-EE, NPCIL Task Forces and the findings of focused regulatory inspections, SARCOP (AERB's apex committee for safety review and enforcement) reviewed and followed-up safety enhancement measures at NPPs. The approach adopted for the review and assessment are outlined below:

- Re-confirmation of capability to withstand currently defined site specific external events and assessment of margins available beyond that.

- Enhancing the capability of the plants to perform the safety functions under extended $\mathrm{SBO} /$ extended loss of heat sink through the design provisions.

- Review of Severe Accident Management programme following an extreme external event. 
These reviews reconfirmed inherent strengths in practices and regulation of NPPs in India, capability to withstand currently defined design basis external events with margins for meeting basic safety functions for beyond design basis events. Based on the above reviews, the measures identified for implementation of the recommendations made for further improving the safety margins in NPPs for external events were identified. These measures have been categorized into short term, medium term and long term, with respect to time frame for implementation, as brought out below:

Short term measures

- Enhancing the reliability of cooling through external hook up points.

- Training and mock-up exercises of operating personnel.

Medium term measures

- Introduction of seismic trip, where it does not exist.

- Strengthening backup power supply (air cooled DGs at higher elevation).

- Strengthening the provision for monitoring of critical parameters under prolonged loss of power.

- Steps for augmentation of onsite water storage, wherever required.

Long term measures

- Enhancing Severe Accident Management programme particularly with respect to hydrogen management and reliable containment venting.

With the implementation of the recommendations made during various reviews carried out in AERB and NPCIL after the accidents at Fukushima NPPs, it is expected that NPPs could be safely brought to cold shutdown state during external events. As a beyond design basis external event may disable the facilities available at the NPP site for monitoring and control of important reactor parameters, post Fukushima reviews have identified the need for creation of an emergency facility at each NPP site which will remain functional under such conditions. The facility will have adequate radiation shielding and will be seismically qualified. It will also have provisions for communication with relevant agencies and for obtaining information from all units at the site to help decide on further course of actions, as also for food, resting, etc. for essential personnel for a period of about one week.

As a part of the existing licensing requirement, every NPP has to establish emergency preparedness and response plans. These plans would ensure that sufficient means exist to cope with an emergency and meet the regulatory requirements. Subsequent to Fukushima accident, National Disaster Management Authority (NDMA), NPCIL and AERB took up review of existing Emergency Preparedness and Response plans at all NPPs to ascertain and evaluate the response and coordination among different agencies during offsite nuclear emergency. Consultations have also been held with state governments on emergency preparedness plans.

AERB formulates safety requirements for nuclear and radiation facilities in the country and has issued safety codes for regulation, siting, design, operation and quality assurance. During the preparation of the regulatory documents, the safety requirements given in IAEA documents and the regulatory agencies of other countries are also considered. Reviews carried out subsequent to Fukushima accident confirmed that the requirements given in AERB regulatory documents are sufficiently conservative. However, AERB will appropriately incorporate the lessons learnt from Fukushima in its regulatory documents. 


\subsection{Developing human resource and maintaining competence}

AERB needs to ensure its core technical competence to reach sound technical judgements in an efficient manner. It is in both the public interest and the regulated industries' interest that the AERB is able to respond to changing environments in the nuclear power industry. AERB has to be both knowledgeable and agile. Presently, AERB has scientific and technical staff strength of around 250. This number is planned to be increased substantially in AERB during the next few years to cater to the additional workload in view of the significant expansion foreseen for the nuclear industry. At the entry level, AERB recruits are trained at nuclear training schools/centres under Homi Bhabha National Institute (HBNI) where formal training is given in the areas of reactor physics, structural analysis, thermal hydraulics, nuclear power plant operation and maintenance, reactor chemistry, health and environment assessment, etc. in the training schools. Some fresh engineers are inducted from nuclear training centres of NPCIL, where training is imparted on the aspects related to O\&M of a NPP. Apart from this, AERB also inducts personnel at postgraduate level from Indian Institutes of Technology (IITs). Experienced personnel of different expertise are also recruited at the middle management level from open market. AERB organises an orientation-training programme for all new recruits on the regulatory activities, which include training modules on the subjects of applicable Acts and Rules, development of regulatory requirements, various safety documents, review and assessment, regulatory inspection and enforcement, etc.

\subsection{Regulating different technologies}

Apart from TAPS-1\&2, all the current operating nuclear power plants are based on PHWR technology. So human expertise and regulatory documents prepared over the years are based on regulatory experience gained during design and operation of PHWRs. However, currently other technologies involving PWRs, FBRs and modernised 700 MWe PHWRs and Advanced Heavy Water Reactor (AHWR) with thorium as fuel are in various stages of deployment. AERB has the challenge of reviewing the design, commissioning and operating aspects of these diverse varieties of reactors. For this purpose, it is important to evolve safety criteria, which are independent of technology. In this connection, guidance is taken from guidelines provided in documents published by IAEA and regulatory bodies of other countries. The interactions with the regulatory bodies of other countries through bilateral meetings and through other international forums are also useful in this regard. Based on these guidelines and interaction and the experience with PHWRs, safety criteria is enunciated for the conceptual level as well as detailed design review of safety systems of plants of various technologies.

\subsection{Security aspects}

The current security scenario around the world is of a major concern. A hostile action against nuclear facilities in the form of sabotage and/or theft or unauthorised removal of material can have adverse impact on the safety and health of workers, public and environment. AERB has been recently entrusted with the responsibility to ensure that the licensee takes adequate measures towards security. This is a relatively new area for AERB and the approach to regulate security aspects is sometimes contradictory to the approach adopted for safety. The policy on security matters should not be transparent as well as consistent. The security systems and procedures need to meet the highest international standards. To meet this objective, some officers of AERB have undergone training courses organised by IAEA on the aspects related to security 
of nuclear facilities. AERB has also initiated development of documents bringing out guidelines regarding design requirement on security systems of nuclear power plants, their operation, surveillance and QA requirements and training and qualification of personnel handling them.

\section{$7.5 R \& D$ support on regulatory issues}

There is worldwide concern relating to the support to safety and regulatory research. Detailed safety research is presently conducted by BARC and IGCAR which are acting as Technical Support Organisations (TSOs) to AERB, as well as by NPCIL to the extent it is required for safe design. Independent regulatory research is important because such research is central to regulatory functions and vital for maintaining core technical competence in the regulatory body. In this regard, AERB has established Safety Research Institute (SRI) at Kalpakkam. However, the areas of research conducted at SRI are very limited with respect to the total dimensions of regulatory research needed. To expand the regulatory research works and to support independent evaluation of safety, AERB sponsors research projects in universities on various issues.

\subsection{Meeting the public expectations}

The biggest challenge lying ahead of India's civil nuclear programme is public acceptance, especially after the accident at Fukushima NPPs. Though AERB has no direct role in promoting the use of nuclear power, it is a great challenge to provide general assurance to public as well as government that the current regulatory approach ensures adequate safety. Towards this, AERB periodically issues press releases to keep the public informed about important regulatory and other related activities. The information on various activities of AERB is also made public through the periodic newsletters and annual reports. Apart from these, relevant information is also provided for queries raised in the Parliament of India and by general public either through direct interaction with senior officers of AERB or under the Right to Information Act.

\section{Conclusions}

The Atomic Energy Regulatory Board of India is now in existence for nearly three decades and during this period it has developed into a mature and effective regulatory body. The AERB has put in place a comprehensive system for design and operational safety review of nuclear power plants in the country. A large number of safety documents have been developed to aid in such reviews. Feed back from operational experience and lessons learned from major incidents both within and outside the country, have been appropriately utilized for modifying designs and procedures for enhanced safety.

Ageing management and safety up-gradation of older NPPs to meet current safety standards has engaged the attention of AERB in recent past. Consequent actions have resulted in incorporation of major safety upgrades and design retrofits in some of the old plants. For the other old plants, required actions have been identified and are being implemented as per an agreed time schedule between AERB and NPCIL.

Today AERB faces new challenges like simultaneous review of a large number of NPP projects with varying designs, a fast growing nuclear power program and functioning of operating plants in a competitive environment. Review and enhancement of the current regulatory requirements to address the enhanced safety expectation following the Fukushima accident is an additional challenge. AERB is gearing itself to meet these challenges in an effective manner. 
Annexure A. List of regulatory documents related to NPPs.

$\begin{array}{llr}\text { Sr. No. Title } & \begin{array}{r}\text { Reference No. with } \\ \text { publication year }\end{array}\end{array}$

\section{Safety Codes}

1. Code of Practice on Safety in Nuclear Power Plant Siting

2. Design of Pressurised Heavy Water Reactor

Based Nuclear Power Plants

3. Nuclear Power Plant Operation

4. Quality Assurance in Nuclear Power Plants

5. Regulation of Nuclear and Radiation Facilities

6. Management of Radioactive Waste

7. Radiation Protection for Nuclear Fuel Cycle Facilities

8. Atmospheric Dispersion and Modelling

9. Hydrological Dispersion of Radioactive Materials

in Relation to Nuclear Power Plant Siting

10. Extreme Values of Mateorological Parameters

11. Hydrogeological Aspects of Siting of Nuclear Power Plants

12. Methodologies for Environmental Radiation Dose Assessment

13. Design Basis Flood for Nuclear Power Plants on Inland Sites

14. Design Basis Flood for Nuclear Power Plants at Costal Sites

15. Site Consideration of Nuclear Power Plants for Off-site Emergency Preparedness

16. Population Distribution and Analysis in Relation to Siting of Nuclear Power Plants.

17. Quality Assurance in Siting of Nuclear Power Plants

18. Seismic Studies and Design Basis Ground Motion for Nuclear Power Plant Sites

19. Safety Classification and Seismic Categorisation for Structures, Systems and Components of Pressurised Heavy Water Reactors

20. Fire Protection in Pressurised Heavy Water Reactor Based Nuclear Power Plants

21. Design Basis Events for Pressurised Heavy Water Reactor

22. Fuel Design for Pressurised Heavy Water Reactors

23. Core Reactivity Control in Pressurised Heavy Water Reactor

24. Primary Heat Transport System for Pressurised Heavy Water Reactors

25. Safety Systems for Pressurised

Heavy Water Reactors

26. Emergency Electric Power Supply Systems for Pressurised Heavy Water Reactor

27. Radiation Protection Aspects in Design for Pressurised Heavy Water Reactor Based Nuclear Power Plants

28. Liquid and Solid Radwaste Management in Pressurised Heavy Water Reactor Based Nuclear Power Plants
AERB/SC/S; 1990

AERB/NPP-PHWR/SC/D

(Rev. 1); 2009

AERB/NPP/SC/O

(Rev. 1); 2008

AERB/NPP/SC/QA

(Rev. 1); 2009

AERB/SC/G; 2000

AERB/NRF/SC/RW; 2007

AERB/NF/SC/RP; 2012

AERB/NF/SG/S-1; 2008

AERB/SG/S-2; 1998

AERB/NF/SG/S-3; 2008

AERB/SG/S-4; 2000

AERB/NF/SG/S-5; 2005

AERB/SG/S-6A; 1998

AERB/SG/S-6B; 2002

AERB/NPP/SG/S-8; 2005

AERB/SG/S-9; 1998

AERB/NPP/SG/S-10; 2005

AERB/SG/S-11; 1990

AERB/NPP-PHWR/SG/D-1; 2003

AERB/SG/D-4; 1999

AERB/SG/D-5; 2000

AERB/NPP-PHWR/SG/D-6; 2003

AERB/SG/D-7; 1998

AERB/NPP-PHWR/SG/D-8; 2003

AERB/NPP-PHWR/SG/D-10; 2005

AERB/SG/D-11; 2002

AERB/NPP-PHWR/SG/D-12; 2005

AERB/NPP-PHWR/SG/D-13; 2002 
Annexure A. (continued).

$\begin{array}{llr}\text { Sr. No. Title } & \begin{array}{r}\text { Reference No. with } \\ \text { publication year }\end{array}\end{array}$

29. Control of Airbone Radioactive Materials in Pressurised Heavy Water Reactors

30. Ultimate Head Sink and Associated Systems in Pressurised Heavy Water Reactor

31. Loss of Coolant Accident Analysis for Pressurised Heavy Water Reactor

32. Safety Related Instrumentation and Control for Pressurised

Heavy Water Reactor Based Nuclear Power Plants

33. Containment System Design for Pressurised Heavy

Water Reactors

34. Vapour Suppression System (Pool Type) for Pressurised Heavy Water Reactor

35. Seismic Qualification of Structures, Systems and Components of Pressurised Heavy Water Reactors

36. Design of Fuel Handling and Storage Systems for Pressurised Heavy Water Reactors

37. Computer Based Systems of Pressurised Heavy Water Reactors

38. Staffing, Recruitment, Training, Qualification and Certification of Operating Personnel of Nuclear Power Plants

39. In-service Inspection of Nuclear Power Plants

40. Operation Limits and Conditions for Nuclear Power Plants

41. Commissioning Procedures for Pressurised Heavy Water

Reactor Based Nuclear Power Plants

42. Radiation Protection During Operation of Nuclear Power Plants

43. Preparedness of the Operating Organization for Handling Emergencies at Nuclear Power Plants

44. Maintenance of Nuclear Power Plants

45. Surveillance of Items Important to Safety in Nuclear Power Plants

46. Management of Nuclear Power Plants for Safe Operation

47. Core Management and Fuel Handling in Operation of Pressurised Heavy Water Reactors

48. Core Management and Fuel Handling in Boiling Water Reactors

49. Management of Radioactive Waste Arising from Operation of Pressurised Heavy Water Reactor Based Nuclear Power Plants

50 Renewal of Authorisation for Operation of Nuclear

Power Plants

51. Operational Safety Experience Feedback on Nuclear

Power Plants

52. Life Management of Nuclear Power Plants

53. Proof and Leakage Rate Testing of Reactor Containments

54. Quality Assurance in the Design of Nuclear Power Plants
AERB/SG/D-14; 2002

AERB/SG/D-15; 2000

AERB/SG/D-18; 2001

AERB/NPP-PHWR/SG/D-20; 2003

AERB/NPP-PHWR/SG/D-21; 2007

AERB/SG/D-22; 2000 2000

AERB/NPP-PHWR/SG/D-23; 2009

AERB/SG/D-24; 2002

AERB/NPP-PHWR/SG/D-25; 2010

AERB/SG/O-1; 1999

AERB/NPP/SG/O-2; 2004

AERB/SG/O-3; 1999

AERB/SG/O-4; 1998

AERB/SG/O-5; 1998

AERB/SG/O-6; 2000

AERB/SG/O-7; 1998

AERB/SG/O-8; 1999

AERB/SG/O-9; 1998

AERB/SG/O-10A; 1998

AERB/SG/O-10B; 1999

AERB/NPP/SG/O-11; 2004

AERB/SG/O-12; 2000

AERB/NPP/SG/O-13; 2006

AERB/NPP/SG/O-14; 2005

AERB/NPP/SG/O-15; 2004

AERB/SG/QA-1; 2001 
Annexure A. (continued).

Sr. No.

55. Quality Assurance in the Procurement of Items and Services for Nuclear Power Plants

56. Quality Assurance in the Manufacture of Items for Nuclear Power Plants

57. Quality Assurance During Site-construction of Nuclear Power Plants

58. Quality Assurance During Commissioning and Operation of Nuclear Power Plants

59. Establishing and Implementing of Quality Assurance Programme for Nuclear Power Plants

60. Assessment of Implementation of Quality Assurance Programme in Nuclear Power Plants

61. Non-conformance Control, Corrective and Preventive Actions for Nuclear Power Plants

62. Document Control and Records Management for Quality Assurance in Nuclear Power Plants

63. Consenting Process for Nuclear Power Plants and Research Reactors

64. Consenting Process for Nuclear Fuel Cycle Facilities and Related Industrial Facilities other than Nuclear Power Plants and Research Reactors

65. Consenting Process for Radiation Facilities

66. Regulatory Inspection and Enforcement in Nuclear and Radiation Facilities

67. Role of the Regulatory Body with Respect to Emergency Response and Preparedness at Nuclear and Radiation Facilities

68. Codes, Standards and Guides to be Prepared by the Regulatory Body for Nuclear and Radiation Facilities

69. Regulatory Consents for Nuclear and Radiation Facilities: Contents and Formats

70. Criteria for Regulation of Health and Safety of Nuclear Power Plant Personnel, the Public and the Environment

71. Classification of Radioactive Waste

72. Predisposal Management of Low and Intermediate Level Radioactive Waste

73. Predisposal Management of High Level Radioactive Waste

74. Near Surface Disposal of Radioactive Solid Waste

75. Management of Radioactive Waste from Mining and Milling of Uranium and Thorium

76. Management of Spent Radioactive Sources and Radioactive Waste Arising from the Use of Radionuclides in Medicine, Industry and Research, including Decommissioning of Such Facilities
Reference No. with

publication year
AERB/SG/QA-3; 1998

AERB/SG/QA-4; 2001

AERB/SG/QA-5; 1993

AERB/NPP/SG/QA-6; 2005

AERB/NPP/SG/QA-7; 2005

AERB/NPP/SG/QA-8; 2006

AERB/NPP/SG/QA-9; 2006

AERB/NPP\&RR/SG/G-1; 2007

AERB/NF/SG/G-2; 2006

AERB/RF/SG/G-3; 2011

AERB/SG/G-4; 2002

AERB/SG/G-5; 2000

AERB/SG/G-6; 2001

AERB/SG/G-7; 2001

AERB/SG/G-8; 2001

AERB/NRF/SG/RW-1; 2011

AERB/NRF/SG/RW-2; 2007

AERB/NRF/SG/RW-3; 2012

AERB/NRF/SG/RW-4; 2006

AERB/NF/SG/RW-5; 2007

AERB/RF/SG/RW-6; 2007 
Annexure A. (continued).

\begin{tabular}{|c|c|c|}
\hline Sr. No. & Title & $\begin{array}{l}\text { Reference No. with } \\
\text { publication year }\end{array}$ \\
\hline 77. & $\begin{array}{l}\text { Decommissioning of Nuclear Fuel Cycle Facilities } \\
\text { other than Nuclear Reactors }\end{array}$ & AERB/NF/SG/RW-7 \\
\hline 78. & $\begin{array}{l}\text { Decommissioning of Nuclear Power Plants } \\
\text { and Research Reactors }\end{array}$ & $\begin{array}{l}\text { AERB/NPP\&RR/SG/RW-8; } \\
2009\end{array}$ \\
\hline 79. & $\begin{array}{l}\text { Geotechnical Aspects and Safety of Foundation for Buildings } \\
\text { and Structures Important to Safety of Nuclear Power Plants }\end{array}$ & AERB/NPP/SG/CSE-2; 2008 \\
\hline 80. & $\begin{array}{l}\text { Material of Construction for Civil Engineering Structure } \\
\text { Important to Safety of Nuclear Facilities }\end{array}$ & AERB/NF/SG/CSE-4 \\
\hline 81. & $\begin{array}{l}\text { Preparation of Site Emergency Preparedness Plans } \\
\text { for Nuclear Installations }\end{array}$ & AERB/SG/EP-1; 1999 \\
\hline 82. & $\begin{array}{l}\text { Preparation of Off-site Emergency Preparedness Plans } \\
\text { for Nuclear Installations }\end{array}$ & AERB/SG/EP-2; 1999 \\
\hline \multirow[t]{2}{*}{83.} & Glossary of Terms for Nuclear and Radiation Safety & AERB/SG/GLO; 2005 \\
\hline & Safety S & \\
\hline 84. & $\begin{array}{l}\text { Civil Engineering Structures Important to Safety } \\
\text { of Nuclear Facilities }\end{array}$ & AERB/SS/CSE; 1998 \\
\hline 85. & $\begin{array}{l}\text { Design of Concrete Structures Important to Safety } \\
\text { of Nuclear Facilities }\end{array}$ & AERB/SS/CSE-1; 2001 \\
\hline 86. & $\begin{array}{l}\text { Design, Fabrication and Erection of Steel Structures Important } \\
\text { to Safety of Nuclear Facilities }\end{array}$ & AERB/SS/CSE-2; 2001 \\
\hline \multirow[t]{2}{*}{87.} & $\begin{array}{l}\text { Design, Fabrication and Erection of Embedded Parts } \\
\text { and Penetrations Important to Safety of Nuclear Facilities }\end{array}$ & AERB/NF/SS/CSE-4; 2003 \\
\hline & Safety & \\
\hline 88. & Civil Engineering \& Building Works of Nuclear Power Plants & AERB/SM/S-1; 1988 \\
\hline 89. & Decommissioning of Nuclear Facilities & AERB/SM/DECOM.-1; 1998 \\
\hline 90. & $\begin{array}{l}\text { Maintenance of Civil Engineering Structures Important } \\
\text { to Safety of Nuclear Power Plants }\end{array}$ & AERB/SM/CSE-1; 2002 \\
\hline 91. & $\begin{array}{l}\text { In-service Inspection of Civil Engineering Structures Important } \\
\text { to Safety of Nuclear Power Plants }\end{array}$ & $\begin{array}{l}\text { AERB/NPP/SM/CSE-2; } \\
2004\end{array}$ \\
\hline 92. & $\begin{array}{l}\text { Quality Assurance during Construction of Civil Engineering } \\
\text { Structures Important to Safety Nuclear Facilities }\end{array}$ & AERB/NF/SM/CSE-3 \\
\hline 93. & $\begin{array}{l}\text { Regulatory Inspection During Construction of Civil Engineering } \\
\text { Structures Important to Safety of Nuclear Facilities }\end{array}$ & AERB/NF/SM/CSE-4; 2011 \\
\hline 94. & $\begin{array}{l}\text { Hydrogen Release and Mitigation Measures under Accident } \\
\text { Conditions in Pressurised Heavy Water Reactors }\end{array}$ & $\begin{array}{l}\text { AERB/NPP-PHWR/SM/D-2; } \\
2004\end{array}$ \\
\hline 95. & $\begin{array}{l}\text { Probabilistic Safety Assessment for Nuclear Power Plants } \\
\text { and Research Reactors }\end{array}$ & $\begin{array}{l}\text { AERB/NPP\&RR/SM/O-1; } \\
2008\end{array}$ \\
\hline 96. & Radiation Protection for Nuclear Facilities & $\begin{array}{l}\mathrm{AERB} / \mathrm{NF} / \mathrm{SM} / \mathrm{O}-2 \text { (Rev. 4); } \\
2005\end{array}$ \\
\hline \multirow[t]{2}{*}{97.} & $\begin{array}{l}\text { Regulatory Inspection and Enforcement in Nuclear Power } \\
\text { Plants and Research Reactors }\end{array}$ & $\begin{array}{l}\text { AERB/NPP\&RR/SM/G-1; } \\
2007\end{array}$ \\
\hline & Technical Documents & \\
\hline 98. & Catalogue of Earthquake $(=>$ M.3.0) in Peninsular India & AERB/TD/CSE-1; 1983 \\
\hline 99. & $\begin{array}{l}\text { Compendium of Standard Generic Reliability Database } \\
\text { for Probabilistic Safety Assessment of Nuclear Power Plants }\end{array}$ & AERB/NPP/TD/O-1; 2006 \\
\hline
\end{tabular}


Annexure A. (continued).

\begin{tabular}{|c|c|c|}
\hline Sr. No. & Title & $\begin{array}{l}\text { Reference No. with } \\
\text { publication year }\end{array}$ \\
\hline 100. & $\begin{array}{l}\text { Human Reliability Analysis: A Compendium of Methods, } \\
\text { Data and Event Studies for Nuclear Power Plants }\end{array}$ & AERB/NPP/TD/O-2; 2008 \\
\hline \multicolumn{3}{|c|}{ Safety Guides on Industrial Safety } \\
\hline 101. & Control of Works & AERB/SG/IS-1 (Rev. 1); 2011 \\
\hline 102. & Personal Protective Equipment & AERB/SG/IS-3; 2004 \\
\hline 103. & $\begin{array}{l}\text { Guidelines for Pre-employment Medical Examination } \\
\text { and Fitness for Special Assignments }\end{array}$ & AERB/SG/IS-4; 2005 \\
\hline 104. & Fire Protection Systems of Nuclear Facilities & $\begin{array}{l}\text { AERB/NF/SS/FPS (Rev. 1); } \\
2010\end{array}$ \\
\hline 105. & $\begin{array}{l}\text { Intervention Levels and Derived Intervention levels } \\
\text { for Off-site Radiation Emergency }\end{array}$ & AERB/SG/HS-1; 1992 \\
\hline
\end{tabular}

\section{Further reading}

AERB 2000a 'Regulation of Nuclear and Radiation Facilities' (AERB/SC/G)

AERB 2000b 'Renewal of Authorization for operation of NPPs' (AERB/SG/O-12)

AERB 2006 'Consenting Process for NPPs \& Research Reactors: Documents Submission, Regulatory Review and Assessment of Consent Application' (AERB/SG/G-1)

Annual Report 2011-12, Atomic Energy Regulatory Board, Mumbai, India

Bajaj S S 2011 Challenges of Atomic Energy Regulation in Indian Context, Atomic Energy Regulatory Board, Mumbai, India. Energy Procedia 7: 55-59

Indian National Report for the $5^{\text {th }}$ review meeting of the Contracting Parties of the Convention on Nuclear Safety, September 2010

Indian National Report for the $2^{\text {nd }}$ extraordinary meeting of the Contracting Parties of the Convention on Nuclear Safety, May 2012

Koley J et al 2006 Regulatory practices for nuclear power plants in India, Atomic Energy Regulatory Board, Mumbai, India. Nucl. Eng. Des. 236: 894-913 